rismo urbano". ${ }^{2}$ No âmbito dessas propostas, privilegiase a constituição de um novo formato para a ação pública, não apenas por meio da liberação de entraves regulatórios sobre a ação dos capitais imobiliários, como ocorreu na Inglaterra da época Thatcher, mas também por meio da participação da iniciativa privada, em "parceria” com a administração local, no desenvolvimento de políticas que aumentem a competitividade urbana.

Modifica-se, então, uma vez mais, os termos da discussão sobre os instrumentos, sendo estes enfocados como potencializadores ou facilitadores da flexibilização e das parcerias. É nesse sentido que a dissertação conclui com uma proposta extremamente interessante e audaciosa: estar-se-ia constituindo um novo padrão de planejamento das cidades, denominado de "planejamento por negociaçôes", definido como "um planejamento comprometido com a negociação e com o estabelecimento de parcerias entre atores públicos e privados" e caracterizado por "operaçóes pontuais, e de contratos de diferentes tipos, a serem negociados, caso a caso, com diversos atores envolvidos ... [com] a função de atender a situações probabilísticas, casuais e inscritas numa infinidade de especificidades locais" (p.148).

Dentre os instrumentos analisados, a autora ressalta que o solo criado e a transferência do direito de construir aproximam-se mais dos princípios e características do planejamento regulatório, enquanto as operações urbanas, operações interligadas, consórcio imobiliário e a urbanização e reurbanização consorciadas seriam mais claramente identificadas com o modelo do planejamento por negociações.

O texto conclui sem uma avaliação clara das positividades ou dos problemas inscritos nessa nova "tendência” apontada. Por um lado, parece que a autora tem uma certa simpatia pela possibilidade aberta pelos novos instrumentos para dar conta das especificidades locais e da imprevisibilidade e da incerteza que seriam constitutivas da produção dos ambientes urbanos. Por outro, também aparece com destaque a incapacidade desses instrumentos em assumir claramente um papel redistributivo, o que é visto como um aspecto negativo. $\mathrm{O}$ que talvez pudesse ser acrescentado, nesse caminho, como uma questão adicional para essa avaliação,

2 Conforme Harvey, D. "Do gerenciamento ao empresariamento: a transformação da administração urbana no capitalismo tardio". Espaço \& Debates, v.16, n.39, 1996. é o problema do rompimento do padrão universalista de intervenção sobre o urbano que marca o enfoque regulatório clássico. Os novos instrumentos, em particular aqueles que caracterizam mais diretamente o planejamento por negociações, ao se legitimarem com base no discurso do aumento da competitividade urbana e da eficiência do poder público, deixam de lado o princípio da norma como uma regulação que se impõe, de forma universal e impessoal, sobre a sociedade. Ao acentuar o caso a caso, o específico e o contrato, caem por terra os princípios da eqüidade, da impessoalidade e do universalismo, valores que sempre legitimaram a intervenção pública. A norma, tornada flexível e negociável, passa a permitir uma distinção que se torna constitutiva da nova relação dos cidadãos com o urbano, de ora em diante: ela vale para todos, menos para alguns, para os que podem negociar ou ser parceiros do poder público. Será possível construirmos cidades democráticas e socialmente justas, com base nesses valores? A leitura desse instigante trabalho nos ajuda, senão a responder, pelo menos a ter bases sólidas para que se possa discutir essa questão.

Adauto Lúcio Cardoso é professor do Instituto de Pesquisa e Planejamento Urbano e Regional da Universidade Federal do Rio de Janeiro.

\section{CONFRONTOS E CONTRASTES REGIONAIS DA CIÊNCIA E TECNOLOGIA NO BRASIL}

Fernando Antônio de Barros

Brasília: Paralelo 15/Universidade de Brasília, 1999.

\section{Brasilmar Ferreira Nunes}

O estudo de Fernando Antônio Barros tem qualidades evidentes. A primeira delas é a oportunidade de retomar uma discussão já clássica dentro das ciências sociais no Brasil, qual seja, a questão regional. Uma temática que teve o seu auge nos anos 60 e que culminou com a institucionalização de instâncias específicas dentro do aparelho de Estado com funções definidas em decorrência das nossas gritantes desigualdades regionais. Um tema que apesar de ainda ser facilmente constatado nas estatísticas oficiais passou para segundo plano nos estudos acadêmicos talvez por uma certa 
perplexidade com a virulência com que vem se dando a inserção da sociedade brasileira nos parâmetros da globalização nesta década final de século. Tudo se passa como se a dimensão espacial mudando de escala colocasse o problema de escanteio.

Uma segunda qualidade decorre justamente de elementos constantes nas apreciações anteriores: ultrapassando a perspectiva analítica centrada na esfera econômica, o estudo abre espaço para se pensar a região a partir de dimensões pouco usuais e mesmo inusitadas. Ultrapassa sobretudo a visão geográfica, colocando-a numa escala justa face as demais. Não se trata no entanto de uma contenda no interior dos campos científicos, tão ao gosto de nossa cultura acadêmica mais conservadora. Ao contrário, a qualidade está na procura de um lugar justo e adequado para cada um dos olhares possíveis de se encarar a questão regional.

$\mathrm{O}$ que vai permitir cumprir a contento a tarefa proposta é, sem dúvida, a opção pela dimensão científica e tecnológica para compreender a lógica de processos sociais - poderíamos dizer culturais (?) - em curso em períodos recentes. Conforme explicitado nas primeiras páginas, o estudo "pretende, assim, contribuir para uma análise mais densamente colocada sobre as desigualdades regionais da base técnico-científica brasileira, aglutinando basicamente dados e reflexôes concernentes à experiência/trajetória da política científica e tecnológica no âmbito regional". Com efeito, as características do sistema de ciência e tecnologia nacionais e sua evolução devem ser examinadas sob a luz das transformaçôes porque passou a sociedade e as suas diferentes formas de inserção no capitalismo internacional. Ao mesmo tempo, pensar a questão regional com base nas características que este sistema assume entre nós pode ser uma entrada interessante para colocar a questão regional na ordem do dia dos debates acadêmicos. Em outras palavras, estamos sempre discutindo as formas de consolidação e mesmo de uma reprodução ampliada de uma sociedade de mercado que, entre nós, da chamada periferia, assume características próprias face a dinâmica desigual e combinada que a qualifica. É neste sentido que a dimensão técnico-científica talvez seja privilegiada para decodificarmos a lógica desta profunda heterogeneidade de nossas sociedades, onde convivem processos produtivos do século passado com outros já do século XXI. Os efeitos sociais desta heterogeneidade são expressos nos índices do desen- volvimento socioeconômico brasileiro quando vistos nas suas espacialidades regionais.

Um outro aspecto que poderia se desdobrar da leitura do documento é a íntima relação entre Estado e Região no Brasil. Este aspecto merece um detalhamento, pois fica-se com a permanente sensação de que os temas privilegiados pelos estudos acadêmicos são sempre aqueles eleitos pela burocracia estatal. De fato, no auge da temática regional no Brasil, o Estado foi eleito como o único capaz de conduzir a sociedade na direção almejada de ultrapassar as condições de desigualdade existentes. Esquecia-se muitas vezes que este Estado tinha objetivos intrínsecos de reproduzir a ordem tal qual ela se apresentava, responsável pelas diferenças. Senão vejamos: Barros se utiliza das reflexões de Sérgio Buarque para argumentar que as atividades técnico-científicas tendem a se distribuir de forma desigual sobre os espaços, acompanhando a acumulaçāao de capital, na medida em que a expansão capitalista necessita do saber como próprio fator de acumulação do capital (p.22). No Brasil, a institucionalização da ciência e da tecnologia vai se dar em atraso face outros países latino-americanos, mas a partir dos anos 50 , com a criação do CNPq e da Capes, a formação de recursos humanos passa a ser um dos fatores estratégicos para garantir a expansão das forças produtivas capitalistas. Citando autores variados, percebe-se na dissertação de Barros que o esforço feito estava pouco articulado, do ponto de vista de compatibilizar a base técnico-científica em fase de implantação e de consolidação com as diferenças regionais. $\mathrm{O}$ resultado foi uma excessiva concentração da capacidade de gerar ciência e tecnologia no eixo Rio/São Paulo. Com o recuo do tempo se percebe claramente que a ciência gerada se adequava a demandas de uma atividade econômica - basicamente industrial - sendo entendida como um apêndice do crescimento em curso.

Posteriormente é que se começa a dar a devida importância à pesquisa como uma efetiva força produtiva, que joga em condiçōes extremamente positivas no sentido de fortalecer o processo de desenvolvimento e de crescimento econômico; talvez pela própria natureza da pesquisa tenhamos dificuldades em perceber a sua importância neste particular. Entretanto, esta importância se solidifica cada vez mais dentro da sociedade brasileira e o reflexo mais evidente é a rotineira criação de instrumentos de ciência e tecnologia culmi- 
nando na institucionalização do Ministério da Ciência e Tecnologia (МСТ) já na Nova República.

O desenvolvimento regional que pouco a pouco passa a ser considerado estratégico para o desenvolvimento nacional vai incorporar a dimensão científica e tecnológica com a criação de programas regionais de P\&D (Pesquisa e Desenvolvimento). A expansão das fronteiras econômicas impõe a necessidade de se conhecer o território nacional em suas potencialidades de crescimento, o que vai implicar a montagem de um complexo arcabouço de pesquisas para o estudo da Amazônia, Nordeste e Centro-Oeste. É a etapa dos grandes programas federais: PIN - Programa de Integração Nacional, Proterra - Programa de Distribuição de Terras, Polamazônia - Programa de Pólos Agropecuários e Agrominerais da Amazônia, Polonordeste Programa de Desenvolvimento de Áreas Integradas do Nordeste, Polocentro - Programa de Áreas Integradas do Centro-Oeste. Dentro de uma série de açôes previstas por estes programas, cabe destacar que todos tinham um componente de C\&T (Ciência e Tecnologia) a ser implementado. Isto significa que esta dimensão se firma como crucial para a expansão da sociedade de mercado então em curso, culminando com a instalação do PTU - Programa do Trópico Úmido e PTSA - Programa do Trópico Semi-Árido, especificamente voltados ao desenvolvimento em C\&T.

O trabalho de Barros é exaustivo na apresentação dos programas regionais de desenvolvimento em que pode ser detectada a variável C\&T. Entretanto o autor chama a atenção para a excessiva centralização dos processos decisórios no interior destes programas, o que implicou um tratamento homogêneo para as regiōes como um todo, sem a mínima atenção às culturas locais e às necessidades em C\&T. Além do mais, "os recursos aplicados tinham caráter mais compensatório, não sendo compatíveis com os necessários para os préinvestimentos ... para transformar a base técnico-científica das regiōes menos favorecidas" (p.41). Mais à frente, enfatiza ainda mais este problema: "as políticas regionais de C\&T dos anos 70 tinham três vieses básicos. Primeiro, apareciam como um apêndice nos planos nacionais para resolverem problemas localizados ou de aspectos estereotipados, como o semi-árido nordestino e a ecologia na Amazônia. Segundo, passava-se a idéia de que uma política reflexo da nacional todos os estados tinham que ter um núcleo de informática, de biotecnologia, etc. Terceiro, a questão regional era equacionada num contexto utópico; não se conhecia de perto as necessidades e os limites de cada região, mas fazia-se planos mirabolantes inclusive sem base de recursos para viabilizá-los" (p.41).

$\mathrm{Na}$ verdade este planejamento cai, como a maioria daqueles estatais, na falácia da igualdade, segundo o qual se parte do princípio de que assumir as diferenças poderia significar assumir, a partir do Estado, as desigualdades; afinal, "somos todos iguais perante a lei". Além do mais poderíamos também destacar a conivência da comunidade científica com este estado de coisas, na medida em que o julgamento por pares nos projetos apresentados para financiamento se guiam por valores universais em que os critérios de cientificidade são comuns a todos. Isto provoca um descolamento da pesquisa de uma realidade local, fazendo que problemas neste nível sejam menos importantes porque pouco valorizados pelos pares. As tecnologias alternativas, que refletiriam uma cultura mais localizada, não encontram aí espaço para se concretizar. $\mathrm{O}$ resultado é o aumento do fosso inter-regional, questão que termina por ser adequada à lógica da globalização, quando então a macro-região praticamente desaparece e o que começa a ser valorizado são os setores produtivos e não os espaços de produção, reduzidos agora à sua dimensão micro.

Barros se debruça exatamente neste aspecto quando vai procurar caracterizar as desigualdades regionais na base técnico-científica do país. Dados atuais e dispersos são sistematizados e permitem caracterizar estas desigualdades inter-regiōes num esforço que termina por escancarar mais uma das dimensões da nossa heterogeneidade. Talvez esteja aí uma das mais gritantes manifestações dos efeitos de décadas de política científica e tecnológica levadas a cabo pelo Estado brasileiro, sobretudo a partir dos anos 50. Por exemplo: 65,96\% dos pesquisadores brasileiros estão na Região Sudeste que detém ainda $3 / 4$ dos nossos doutores. Isto termina por implicar que esta região conta com $68,5 \%$ dos grupos de pesquisa do país, chegando ao absurdo de registrar o dado que aponta que $88,25 \%$ dos mestres e 97,32\% dos doutores do país estão entre Rio Grande do Sul e Minas Gerais, com São Paulo e o Espírito Santo nos extremos superior e inferior. Estes dados vão incidir de forma objetiva em todo e qualquer indicador da base técnico-científica quando regionalizada. Poderíamos argumentar que a pesquisa se desenvolve por es- 
tímulos emitidos pela base econômica que demanda conhecimentos para alimentar a sua própria dinâmica; desta forma justificaríamos a sua incidência no Sudeste do país e, em menor escala, no Sul. Poderíamos também argumentar que a população se concentra nestes dois subterritórios e que também seriam maiores as chances de concentração de cientistas nestas regiōes. Claro que indo nesta direção teríamos que supor que países com superpopulação teriam bases técnico-científicas mais complexas e sofisticadas. De fato, não é bem assim que as coisas se passam.

Enfim, por qualquer ângulo que tentarmos explicar esta realidade, não se pode jamais esquecer que no caso brasileiro o principal agente do desenvolvimento científico é o Estado, aliás muito mais importante do que, por exemplo, as atividades econômicas tout-court. Até o momento, no Brasil, estudar a dinâmica científica é sinônimo de estudar o Estado; sem a sua presença certamente nossa base técnico-científica seria completamente diferente, sobretudo levando em conta que os grupos econômicos nacionais raramente investem em P\&D. O trabalho de Barros comprova esta assertiva, a qual já está devidamente discutida em inúmeros trabalhos acadêmicos, que terminam por passar sutilmente um recado: o empresário schumpeteriano, visto pela sua capacidade de impulsionar o desenvolvimento científico e tecnológico nacional, é tudo menos brasileiro.

No momento em que Barros vai discutir as dificuldades intrínsecas do desenvolvimento científico e tecnológico (p.57ss.) é que se mostra o verdadeiro impasse da questão. As prioridades em $\mathrm{P} \& \mathrm{D}$ são escolhas entre dois tipos de lógicas: a do conhecimento científico e a das necessidades da economia e, num sentido mais amplos da sociedade (p.58). Em última instância as coisas se passam segundo um modelo impulsionado por um "mercado científico" e um outro impulsionado pelo "mercado econômico e social". Se nos prendermos ao papel estratégico desempenhado pelo Estado, iremos nos dar conta de que no caso brasileiro são raros os exemplos em que predomina o primeiro impulso. $\mathrm{O}$ nosso "mercado científico" enfrenta uma difícil batalha para fazer prevalecer o seu ethos. A forma segundo a qual se dá nossa inserção na lógica mundializada da reprodução do capital torna as coisas ainda mais complexas, ficando cada vez mais difícil romper o círculo que nos mantém periféricos com relação aos centros dinamizadores do conhecimento científico e tecnológico.
De todas estas considerações surge ainda uma outra que poderia ser assim explicitada: finalmente, para que colocar como situação desejável uma distribuição mais eqüitativa no território nacional de uma base técnico-científica? Finalmente, como bem salienta Barros fazendo uso de bibliografia especializada, nos Estados Unidos, por exemplo, a base técnico-científica de ponta está concentrada em poucos Estados e poucas instituições: apenas cinco Estados absorvem $46 \%$ do dispêndio nacional em C\&T, enquanto 25 dos 51 existentes são responsáveis pela quase totalidade desse dispêndio. Aí está talvez um dos nós da questão e que nos coloca na posição de sociedade de terceiro mundo: lá a absorção da tecnologia se dá de forma bastante homogênea, pois mesmo naqueles Estados, onde são praticamente inexistentes atividades em $P \& D$, a educação é acessível e portanto a absorção do conhecimento gerado é mais factível. Retornamos assim, no caso brasileiro, a nosso eterno problema: elevado índice de analfabetismo, excessiva concentração de renda impossibilitando o acesso ao consumo monetarizado por parcelas enormes da população e, portanto, uma $\mathrm{P} \& \mathrm{D}$ que termina por se adequar numa sociedade extremamente hierarquizada, cujos resultados são acessíveis sobretudo aos altos escalóes desta hierarquia.

Neste contexto, nossa realidade aparece com toda sua especificidade: produzimos ciência num certo patamar do avanço internacional mas as possibilidades de socializar o conhecimento gerado são extremamente limitadas provocando, em última instância, um distanciamento do cientista da base social que o sustenta e que poderia the garantir um certo grau de legitimidade. Mesmo assim, pesquisa de opinião efetuada para o CNPq no início desta década demonstrou que o brasileiro tem um elevado grau de confiança na ciência e no cientista. Não deixa de ser um resultado instigante...

Finalmente, é oportuno insistir na importância do trabalho desenvolvido por Barros em sua dissertação. A ANPUR foi bastante feliz em premiá-lo e, sem dúvida, trata-se de um texto que permite inúmeras reflexōes adicionais; algumas delas tentei expressar de forma rápida nestas linhas. Este é, a meu ver, o verdadeiro valor de um trabalho científico.

Brasilmar Ferreira Nunes é professor titular do Departamento de Sociologia da Universidade de Brasilia. 